Analytical Modeling of the High-Velocity Impact of Autoclaved Aerated Concrete (AAC) Blocks and Some Experimental Results

Amar Bayat, Gholam Hossein Liaghat, Mehran Ghalami-Choobar, Ghasem Dehghani Ashkezari , Hadi Sabouri

PII:

DOI:

Reference:

To appear in:

Received date: Revised date:

Accepted date:
S0020-7403(19)30226-7

https://doi.org/10.1016/j.jimecsci.2019.05.043 MS 4949

International Journal of Mechanical Sciences
19 May 2019

27 May 2019

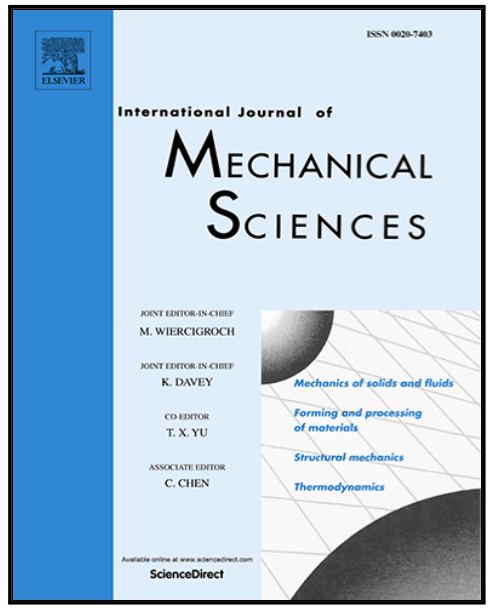

Please cite this article as: Amar Bayat, Gholam Hossein Liaghat, Mehran Ghalami-Choobar, Ghasem Dehghani Ashkezari, Hadi Sabouri , Analytical Modeling of the High-Velocity Impact of Autoclaved Aerated Concrete (AAC) Blocks and Some Experimental Results, International Journal of Mechanical Sciences (2019), doi: https://doi.org/10.1016/j.ijmecsci.2019.05.043

This is a PDF file of an unedited manuscript that has been accepted for publication. As a service to our customers we are providing this early version of the manuscript. The manuscript will undergo copyediting, typesetting, and review of the resulting proof before it is published in its final form. Please note that during the production process errors may be discovered which could affect the content, and all legal disclaimers that apply to the journal pertain. 


\section{Highlight}

- High velocity impact behavior of Autoclaved aerated concrete (AAC) was studied.

- An analytical model was presented to predict the residual velocity of projectile.

- Four energy absorption mechanism considered to predict impact behavior accurately.

- The model validated by comparison of model results with those of experiments.

- The validated model was employed for parametric study and sensitivity analysis. 


\title{
Analytical Modeling of the High-Velocity Impact of Autoclaved Aerated Concrete (AAC) Blocks and Some Experimental Results
}

\author{
Amar Bayat ${ }^{1}$, GholamHossein Liaghat ${ }^{1,2^{*}}$, Mehran Ghalami-Choobar ${ }^{1}$, Ghasem Dehghani \\ Ashkezari $^{3}$, Hadi Sabouri ${ }^{4}$ \\ ${ }^{1}$ Department of Mechanical Engineering, Tarbiat Modares University, Tehran, Iran \\ 2 Department of Mechanical Engineering, Kingston University, London, U.K. \\ ${ }^{3}$ Malek Ashtar University of Technology, Tehran, Iran. \\ ${ }^{4}$ Department of Mechanical Engineering, Kharazmi University, Tehran, Iran.
}

\begin{abstract}
This paper presents an analytical model for the high-velocity impact behavior of autoclaved aerated concrete (AAC) blocks under flat-ended cylindrical projectile. This model employs an energy balance approach to derive the governing differential equations related to the process. The model considers four energy absorbing mechanisms including crushing, tensile fracture, plug kinetic, and friction loss. A closed-form solution was presented to the derived governing differential equations using singularity functions. Singularity functions were used to incorporate discontinuities due to various energy absorbing mechanisms. Results of the present model are reasonably in good agreement with presented experimental results. The effects of various impact parameters on the residual velocity and energy absorption were studied and the results are reported, discussed and commented upon.
\end{abstract}

\section{Keywords:}

High-velocity impact, AAC blocks, Flat nosed projectile, Closed-form solution.

*Corresponding author: Ghlia530@modares.ac.ir 


\section{Introduction}

Autoclaved aerated concrete (AAC) is a type of precast concrete materials and comparing to normal concrete has a low density and excellent insulation properties. The low density is achieved by the formation of air voids to produce a cellular structure. The advantages of cellular material (ie: foams[1, 2], honeycombs[3]) make them popular in automotive and aerospace industries and constructions because of having great impact energy absorption[4]. AACs composed of natural raw materials including cement, lime, water, sand and Aluminum powder which make the mixture to expand and have a porous structure due to producing hydrogen bubbles. Some of the benefits of using AAC include highly fire resistance, recyclability and low density which leads to easy handling and installation. The increased thermal efficiency of AAC makes it suitable for use in areas with extreme temperatures, as it eliminates the need for separate materials for construction and insulation, leading to faster construction and cost-saving.

Mechanical behavior of different materials suited for construction purposes has been a common research subject. Cement-based materials as the most important group have a great proportion in these researches. Ficker [5] presented some analytical consequences which follow from the results published about the quasi-static compressive strength of cement-based materials. Costa et al [6] assessed the in-plane response of unreinforced AAC masonry panels through an experimental test campaign in order to obtain a reliable description of the lateral cyclic behavior. Jiang et al [7] investigated the preparation process and properties of high-porosity foamed concretes. It was shown that the insulation of humidity during the curing process increases the strength of foamed concretes. Mechanical response of textile-reinforced aerated concrete sandwich panels was investigated by Dey et al[8] using an instrumented three-point bending experiment under static and low-velocity dynamic loading. Modeling crack development in beams and deep-beams made of autoclaved aerated concrete performed by Ferretti et al[9]. Experimental investigation of dynamic behavior and damping ability of autoclaved aerated concrete subjected to a mechanical shock or blast, performed by Mespoulet et al [10]. 
Some researchers conducted investigations on the impact behavior of cement-based materials [11-14]. Yankelevsky and Avnon [15] studied some of the dynamic characteristics of AAC walls under the localized high-intensity impact, such as the number of cracks and their dependence on the boundaries location. Verma et al [16] performed an analytical, numerical and experimental investigation of low energy impact behavior of Ultra-High-Performance Concrete (UHPC) and proposed an algorithm to calculate optimum thickness for UHPC panels. Impact Response of Autoclave Aerated Concrete/FRP Sandwich Structures was the subject of study of Nasim et al[17]. Evaluation of the response of AAC/CFRP sandwich structures to low-velocity impact was performed by Serrano-Perez et al [18], they also compared the experimental results to the predicted energy absorptions values given by an energy balance model. Dey et al [19] presented an impact response of fiber-reinforced aerated concrete under a three-point bending configuration based on the free-fall of an instrumented impact device. The performances of autoclaved aerated concrete masonry walls subjected to vented gas explosions were investigated by $\mathrm{Li}$ et al[20].

Using analytical modeling to predict the impact behavior of structures[21-23] reduces the costs of specimen fabrication and omits the need for the long computational time of numerical methods. To the best knowledge of authors, the high-velocity impact response of AAC has not been yet studied analytically in literature. Therefore, the purpose of this paper is to present an analytical modeling of high-velocity impact behavior of autoclaved aerated concrete targets subjected to a rigid cylindrical projectile. An energy balance approach is employed to derive the governing differential equations of the impact behavior of AAC. A closed-form solution utilizing singularity function is presented for the obtained governing equation. The proposed mathematical model is yalidated with the gas gun test apparatus results. A parametric study is carried out to evaluate the role of thickness, projectile mass, and initial velocity in AAC mechanical behavior.

\section{Experimental procedure}

\subsection{Preparation of Specimens}

Pre-produced AAC blocks manufactured by Parin Beton Amood Company were utilized to produce the impact test specimens. The $125 \times 125 \times 50 \mathrm{~mm}$ impact test specimens were cut from the initial blocks with dimensions of $600 \times 200 \times 250 \mathrm{~mm}$. Figure 1 shows the specimen before the test. Also, Table 1 shows the mechanical properties provided by the AAC blocks manufacturer. 
Figure 1:(a) Manufactured AAC block and (b) specimen for impact tests.

Table 1: Mechanical properties of AAC block.

\subsection{Through-thickness compressive strength of the AAC blocks}

Quasi-static punch test was carried out to determine the compressive strength of AAC blocks in thickness direction using Universal Testing Machine (UTM) of Impact Laboratory of the Tarbiat Modares University. To apply the clamped boundary condition, a hardened steel fixture (Figure 2) was employed. Figure 3 illustrates the stress-displacement curve obtained by employing forcedisplacement output data of UTM.

Figure 2: Schematic diagram (a, b) and photograph (c) of clamping fixture.

Figure 3: Stress- displacement curve obtained by quasi static experimental tests.

Following bi-linear function incorporated in the curve fitting process to achieve Stressdisplacement curve in Figure 3.

$\sigma_{c}(x)=\sigma_{e} x\left(\langle\mathrm{x}-0\rangle^{0}-\left\langle\mathrm{x}-x_{e}\right\rangle^{0}\right)+\sigma_{e} x_{e}\left\langle\mathrm{x}-x_{e}\right\rangle^{0}+\sigma_{h}\left\langle\mathrm{x}-x_{e}\right\rangle^{1}$

where $\sigma_{c}, \sigma_{e}, \sigma_{h}$ are curve fitting constants. It is worth noting that $<$ indicates Macaulay's parentheses and defined as follows:

$$
\langle x-a\rangle^{n}= \begin{cases}(x-a)^{n} & x \geq a \\ 0 & x<a\end{cases}
$$

\subsection{High-velocity impact tests}

Figure 4 shows the gas gun apparatus in the Impact Laboratory of Tarbiat Modares University used for impact tests to be performed. Specifications of the flat-nosed projectile are given in Table 2. Input and residual velocities measured using two chronographs placed before and after the target fixture. The employed chronograph can measure particle velocities between 9 to 2100 $\mathrm{m} / \mathrm{s}$, according to datasheet. Utilizing the chronograph to measure the velocity of projectile in the wide range have been reported in some researches [24, 25]. Cardboard was placed before the last chronograph to eliminate the small flying particles separated from the target. Because these highvelocity small particles can be detected by the chronograph and result in wrong exit veloctiy measurement.

Table 2. The geometry of hardened projectile. 
Figure 4: Gas gun apparatus used for experimental test (a) main structure, (b) high-pressure reservoir and solenoid valve[26].

\section{Mathematical modeling}

\subsection{Theoretical background}

In this study, a rectangular AAC thick plate or block subjected to the high-velocity impact caused by a flat-nosed projectile is modeled by the energy balance approach. Figure 5 demonstrates a schematic diagram of impact initiation.

Figure 5: Schematic diagram of AAC block subjected high-velocity projectile.

It is assumed that the kinetic energy of the projectile $E_{k}$ will be absorbed by four different mechanisms: AAC crushing $E_{c}$, tensile fracture energy $E_{t}$, plug kinetic energy $E_{m}$ and friction $\operatorname{loss} E_{f}$. Elastic deformation could be neglected in brittle materials compared to the failure modes observed in energy absorption processes [27,28]. In order to take the strain rate effects on the strengths of AAC blocks into account, statically obtained strengths are multiplied by dynamic factor [29]. The dynamic factor for AAC blocks is 1.45 according to Mespoulet and et al[10]. A new model to predict the high-velocity impact of AAC including mentioned failure mechanisms are developed based on the model presented in [30].

$d E_{k}=d E_{c}+d E_{t}+d E_{m}+d E_{f}$

where differential energy terms can be determined as follows:

- Kinetic energy of the projectile

For the sake of simplification, instead of temporal integration, a spatial variable describing the position of the projectile ( $\mathrm{x}$ ), is used. Differential energy loss between position $\mathrm{x}$ and $\mathrm{x}+\mathrm{dx}$ is given by

$d E_{k}(x)=\frac{1}{2} m_{p} d\left(v(x)^{2}\right)$

where $m_{p}$ and $v(x)$ denote mass and velocity of the projectile respectively.

- Energy absorbed by AAC crushing 
The out of plane shear stresses caused by normal contact of projectile create a cylindrical hole. The associated energy with the crushing process may be calculated by

$d E_{c}(x)=\sigma_{c}(x) A d x$

where $\sigma_{c}(x)$ and $A$ are the through-thickness compressive strength of the AAC and frontal area of the projectile, respectively. The function $\sigma_{c}(x)$ was defined in section 2.2 .

- Tensile fracture energy

Examining the impacted AAC blocks after sectioning shows another energy absorbing mechanism. The energy absorbed by this mechanism can be determined as:

$d E_{t}(x)=u_{t} d \forall(x)$

where $u_{t}$ denotes tensile fracture specific energy and $d \forall(x)$ is volume of the elastic wave affected region for increment $d x$. Due to the elastic behavior of AAC block under tensional stress, the specific energy can be calculated by

$u_{t}=2\left(\frac{1}{2} f_{t} \varepsilon_{f}\right)$

where $f_{t}$ and $\varepsilon_{f}$ are ultimate tensile strength and failure strain of AAC block, respectively. It should be noted the multiplier 2 is considered to account for symmetrical in-plane biaxial stresses. Since the scalar expression in parentheses in $\mathrm{Eq}(7),\left(1 / 2 f_{t} \varepsilon_{f}\right)$, is valid for uniaxial stress state, factor of two is considered to include the symmetrical in-plane biaxial stresses in the impacted target.

Examining impacted blocks reveals the truncated conical shape of the tensile fracture zone (Figure6).

Figure 6: Through section (a) view of theAAC specimen and (b) schematic of the truncated conical shape.

The volume of the differential disk element can be determined as follows (See Figure 6):

$d V=\pi R^{2} d x=\pi\left(r+\left(x-x_{0}\right) \tan \theta\right)^{2} d x$

where $R, r, x_{0}$ and $\theta$ are element instant radius, projectile radius, the position of the tension fracture region and semi-angle of the tension affected zone, respectively. It should be noted that 
$x_{0}$ and $\theta$ are measured experimentally from impacted blocks which are $32 \mathrm{~mm}$ and $57^{\circ}$, respectively. Since the mechanism of tensile fracture occurs at the position interval $x_{0}<x<h$, Cut off function $C_{r}(x)$ is defined as:

$C_{r}(x)=\left\langle x-x_{0}\right\rangle^{0}-\langle x-h\rangle^{0}$

- Plug kinetic energy

Translational motion of the projectile accelerates the particles of the AAC block which are in front of the projectile. The kinetic energy of the mentioned section of the AAC block could be written as:

$d E_{m}(x)=\frac{1}{2}\left(A d x \rho_{l}\right) v^{2}(x)$

where $\rho_{l}$ denotes the dry density of the AAC.

- Energy absorbed by Friction loss

Maximum normal reaction force, $F_{r}$, applied to the outer curved surface area of the hole created by the projectile during penetration of the AAC block can be estimated by crushing strength $F_{r}=\sigma_{c}(x) A^{\prime}$. Also, friction force, $F_{f}$, can be calculated based on the normal reaction force $F_{f}=\mu F_{r}$. Therefore, energy absorption during increment dx can be estimated as:

$d E_{f}(x)=\mu \sigma_{c}(x) A^{\prime} d x$

where $A^{\prime}$ and $\mu$ denote the surface area of the side of the projectile and sliding friction coefficient, respectively.This friction coefficient for concrete-steel contact surface is $0.02[31]$.

\subsection{Deriving the governing equations}

Substituting Eqs (4), (5), (6), (10) and (11)into (3) and rearranging it yields the governing equation of the problem as: 
$\frac{1}{2} m_{p} \frac{d\left(v(x)^{2}\right)}{d x}=\sigma_{c}(x) A+\frac{1}{2}\left(A \rho_{l}\right) v^{2}(x)+\mu \sigma_{c}(x) A+$

$\pi f_{t} \varepsilon_{t}\left(r+\left(x-x_{0}\right) \tan \theta\right)^{2} C_{r}(x)$

$v(0)=v_{i}$

Eq (12) is an initial value problem that can be solved numerically or analytically by the RungeKutta method or singularity functions as described in Section 3.3.

In order to simplify the parametric study, following non-dimensional variables are defined

$v^{*}=\frac{v}{v_{i}}, x^{*}=\frac{x}{h} \quad, \sigma_{c}^{*}\left(x^{*}\right)=\frac{\sigma_{c}\left(x^{*}\right)}{\sigma_{0}}, \omega^{*}=\left(v^{*}\right)^{2}$

Substituting Eq (13)into (12) and doing some manipulation non-dimensional governing equation can be obtained.

$\frac{d \omega^{*}}{d x^{*}}=\left(R_{c}+R_{f}\right) \sigma^{*}+R_{t}\left(1+\left(x * \frac{h}{r}-\frac{x_{0}}{r}\right) \tan \theta\right)^{2} C_{r}(x)+R_{m} \omega^{*}$

$\omega^{*}(0)=1$

where

$R_{c}=\frac{2 \sigma_{0} h A}{m_{p} v_{i}^{2}}$

$R_{m}=\frac{h A \rho_{l}}{m_{p}}$

$R_{f}=2 \mu \frac{\sigma_{0} A h}{m_{p} v_{i}^{2}}$

$R_{t}=\frac{2 \pi f_{t} \varepsilon_{t} r^{2} h}{m_{p} v_{i}^{2}}$

\subsection{Closed form solution}

for the sake of simplicity Eq (14) rearranged in the following form, 
$\frac{d \omega(x)}{d x}+N_{2} \omega(x)=-N_{1} \sigma_{c}(x)-N_{3} \sigma_{c}(x)-N_{4}\left(r+\left(x-x_{0}\right) \tan \theta\right)^{2} C_{r}(x)$

where

$N_{1}=\frac{2 A}{m_{p}}$

$N_{2}=\frac{A \rho_{l}}{m_{p}}$

$N_{3}=\frac{4 \mu A}{m_{p} r^{2}}$

$N_{4}=\frac{2 \pi f_{t} \varepsilon_{t}}{m_{p}}$

Eq (16) is a first order ODE, and its general solution can bewritten as:

$\omega(x)=\frac{1}{u(x)}\left[\int(u(x) q(x)) d x+C_{1}\right]$

$P(x)=N_{2}$

$u(x)=e^{\int P(x) d x}=e^{N_{2} x}$

$\mathrm{q}(x)=-\left(N_{1}+N_{3}\right) \sigma_{c}(x)-N_{4}\left(r+\left(x-x_{0}\right) \tan \theta\right)^{2} C_{r}(x)$

$\int u(x) \mathrm{q}(x)=-\int e^{R_{m} x}\left(\left(N_{1}+N / 3\right) \sigma_{c}(x)+N_{4}\left(r+\left(x-x_{0}\right) \tan \theta\right)^{2} C_{r}(x)\right) d x$

After some mathematical manipulations, the final form of non-dimensional $\omega$ can be expressed as:

$\omega(x)=f_{0}(x)\langle\mathrm{x}-0\rangle^{0}+f_{1}(x)\left\langle\mathrm{x}-x_{e}\right\rangle^{0}+f_{2}(x)\left\langle x-x_{0}\right\rangle^{0}+f_{3}(x)\langle x-h\rangle^{0}+C_{1}$

where $f_{i}, i=0-3$ are given in Appendix A. «> denotes Macaulay's parentheses. It should be noted $C_{1}$, integration constant, is determined using the initial velocity of the projectile.

$C_{1}=v_{i}^{2}-\sigma_{e} \frac{\left(N_{1}+N_{3}\right)}{N_{2}^{2}}$

\section{Results and discussion}

\subsection{Validation}


In this section, results obtained by the presented model are compared to those of experimental tests. as can be seen in Figure 7 there is a good agreement among results and this model can reasonably predict the accurate value of the ballistic limit velocity of the AAC block when subjected to the high-velocity impact of a rigid cylindrical projectile

Figure 7: Comparison of residual velocity obtained by the proposed analytical model and those of experiment.

\subsection{Sensitivity analysis}

To study the relative significance of various energy absorption mechanisms, a variation of nondimensional parameters, Eq (15), is considered. Figure 8 (a) depicts the variation of nondimensional parameters for the four above-mentioned mechanisms as a function of the initial velocity. As can be seen, the crushing and friction associated mechanisms are dominant slightly above the ballistic limit while in higher velocities the tensile fracture energy is almost negligible. Figure 8 (b) compares the fraction contributions value of different energy absorbing mechanisms in perforation energy for a wide range of input velocities. When input velocity increases, the fraction contributions value of the momentum mechanism rises. However, the crushing and tensile fracture mechanisms have not similar trends and the fraction contributions value of these mechanisms decreases as input velocity increases.

Figure 8: Comparison of (a) non-dimensional parameters(b) relative importance of various energy absorption mechanisms for various input velocities obtained by the proposed analytical model.

\subsection{Parametric study}

In this section, the influence of various parameters such as projectile mass, projectile radius, input velocity)and target thickness on high-velocity impact behavior of the AAC blocks is studied

\subsubsection{Effect of projectile mass}

Figure 9 (a) demonstrates a comparison of the projectile velocity during the penetration process for four different projectile's mass. It should be noted that different masses obtained by 
changing projectile density. In the meantime, the other parameters remained unchanged. As can be seen, increasing the mass leads to residual velocity to be increased. since higher mass corresponds to higher initial kinetic energy. Figure 9 (b) depicts the variation of the perforation of energy for different projectile mass with the same input velocity. The results show that the AAC blocks have more capacity of energy absorption for heavier projectiles. The findings are compatible with those reported for composite laminate[30].

Figure 9: (a) Variation of residual velocity for different projectile mass during the impact process. (b) Energy absorption vs. mass projectile.

\subsubsection{Effect of projectile radius}

Figure 10 (a) depicts the influence of the projectile radius on the variation of projectile velocity during the perforation process when other parameters such as velocity and mass are held constant. Four radii $\frac{r}{2}, \mathrm{r}, \frac{3 r}{2}, 2 r$ and $m_{p}=8.94 \mathrm{gr}$ are assumed. The figure indicates that as projectile radius rises the residual velocity falls. Because increasing the projectile frontal area, $A$ , causes increasing of the energy absorption caused by crushing and momentum. Furthermore, Figure 10 (b) shows the perforation energy for different radii. As can be seen, perforation energy increases while the projectile radius increases. But the increasing rate of perforation energy for large projectiles are lower than the small ones.

Figure 10: (a) Variation of residual velocity vs. projectile position for different radii of projectiles. (b) Energy absorption vs. radius projectile.

\subsubsection{Effect of input)velocity}

To evaluate the effect of input velocity on high-velocity impact behavior of the AAC blocks five initial velocities are chosen. As can be observed in Figure 11 (a) when the input velocity increases, the residual velocity rises. Figure 11 (b) illustrates the effect initial velocity on the perforation energy of the AAC blocks. The results show an increasing trend of perforation energy in terms of initial velocities. The above results indicate a similar trend to those reported by Ghalami and Sadighi [32] for the sandwich panel. 
Figure 11: (a) Variation of residual velocity during the impact process for different input velocities of the projectile.

(b) Energy absorption vs. Input velocity.

\subsubsection{Effect of target thickness}

Figure 12 (a) depicts a comparison of projectile velocities for targets with different thicknesses. When target thickness increases, residual velocity drops and finally becomes zero. For thick targets, the value of the energy absorption of the AAC block is greater than that of thinner ones while the rate of increase falls (see Figure 12 (b) ). It is shown that the residual velocity and therefore ballistic limit velocity will increase with target thickness. These results are compatible with those of [33]for concrete.

Figure 12: (a) Variation of residual velocity vs. projectile position for the different thicknesses of targets. (b) Energy absorption vs. target thickness.

\section{Conclusions}

In this paper, an analytical model for the high-velocity impact behavior of autoclaved aerated concrete (AAC) blocks under flat-nosed cylindrical projectile was presented. A closed-form solution was presented using singularity functions. The results obtained by the present model are in good agreement with those of the experiment. The effects of the various factors such as target thickness, projectile mass, projectile radius, and initial velocity were examined on the variation of projectile velocity during the process.

Following conclusions could be mentioned:

- The presented model provides an accurate prediction of high-velocity impact behavior of AAC blocks under study.

- Momentum mechanism plays an important role in the prediction of the energy absorption in higher velocities.

- Presented closed-form solution provides simple and efficient which could be employed in the primary design of AAC blocks

\section{Acknowledgment}


The authors are thankful for financial support of Tarbiat Modares University, also for technical support of Mr Ahmadi, managing director of Parin Beton.

\section{References}

[1] Elnasri I, Zhao H. Impact perforation of aluminium Cymat foam. International Journal of Mechanical Sciences. 2019;150:79-89.

[2] Lu G, Shen J, Hou W, Ruan D, Ong L. Dynamic indentation and penetration of aluminium foams. International journal of mechanical sciences. 2008;50:932-43.

[3] Hassanpour Roudbeneh F, Liaghat G, Sabouri H, Hadavinia H. Experimental investigation of quasistatic penetration tests on honeycomb sandwich panels filled with polymer foam. Mechanics of Advanced Materials and Structures. 2018:1-13.

[4] Zhao H, Elnasri I, Abdennadher S. An experimental study on the behaviour under impact loading of metallic cellular materials. International Journal of Mechanical Sciences. 2005;47:757-74.

[5] Ficker T. Quasi-static compressive strength of cement-based materials. Cement and Concrete Research. 2011;41:129-32.

[6] Costa AA, Penna A, Magenes G. Seismic performance of autoclaved aerated concrete (AAC) masonry: from experimental testing of the in-plane capacity of walls to building response simulation. Journal of Earthquake Engineering. 2011;15:1-31.

[7] Jiang J, Lu Z, Niu Y, Li J, Zhang Y. Study on the preparation and properties of high-porosity foamed concretes based on ordinary Portland cement. Materials \& Design. 2016;92:949-59.

[8] Dey V, Zani G, Colombo M, Di Prisco M, Mobasher B. Flexural impact response of textilereinforced aerated concrete sandwich panels. Materials \& Design. 2015;86:187-97.

[9] Ferretti D, Michelini E, Rosati G. Cracking in autoclaved aerated concrete: Experimental investigation and XFEM modeling. Cement and Concrete Research. 2015;67:156-67.

[10] Mespoulet J, Plassard F, Hereil PL. Strain rate sensitivity of autoclaved aerated concrete from quasi-static regime to shock loading. EPJ Web of Conferences: EDP Sciences; 2015. p. 01053.

[11] Seifoori S, Liaghat G. A semianalytical and numerical study of penetration and perforation of an ogive-nose projectile into concrete targets under normal impact. Proceedings of the Institution of Mechanical Engineers, Part C: Journal of Mechanical Engineering Science. 2011;225:1782-97.

[12] Yang H-w, Jin X-c, Zhang J, Wang Z-h, Wang Z-y. Analysis on mass loss of different sized projectiles penetrating into concrete targets. International Journal of Mechanical Sciences. 2017;131:683-92.

[13] Li Q, Reid S, Wen H, Telford A. Local impact effects of hard missiles on concrete targets. International Journal of impact engineering. 2005;32:224-84.

[14] Tong L, Yu Y, Xu C. Nonlinear dynamic behavior of cemented granular materials under impact loading. International Journal of Mechanical Sciences. 2019;151:70-5.

[15] Yankelevsky DZ, Avnon I. Autoclaved aerated concrete behavior under explosive action. Construction and Building Materials. 1998;12:359-64.

[16] Verma M, Prem PR, Rajasankar J, Bharatkumar B. On low-energy impact response of ultrahigh performance concrete (UHPC) panels. Materials \& Design. 2016;92:853-65. 
[17] Uddin N, Shelar KV, Fouad F. Impact response of autoclave aerated concrete/FRP sandwich structures. Structures Congress 2006: Structural Engineering and Public Safety2006. p. 1-10.

[18] Serrano-Perez JC, Vaidya UK, Uddin N. Low velocity impact response of autoclaved aerated concrete/CFRP sandwich plates. Composite structures. 2007;80:621-30.

[19] Dey V, Bonakdar A, Mobasher B. Low-velocity flexural impact response of fiber-reinforced aerated concrete. Cement and Concrete Composites. 2014;49:100-10.

[20] Li Z, Chen L, Fang Q, Hao H, Zhang Y, Chen W, et al. Study of autoclaved aerated concrete masonry walls under vented gas explosions. Engineering Structures. 2017;141:444-60.

[21] Ghalami-Choobar M, Liaghat G, Sadighi M, Ahmadi H. Eccentric low-velocity impact on fiber-metal laminates under in-plane loading using unified zigzag theory. Composite Structures. 2018;201:315-25.

[22] Zhang J, Lin Z, Wong A, Kikuchi N, Li V, Yee A, et al. Constitutive modeling and material characterization of polymeric foams. Journal of engineering materials and technology. 1997;119:284-91.

[23] Ling C, Ivens J, Cardiff P, Gilchrist MD. Deformation response of EPS foam under combined compression-shear loading. Part I: Experimental design and quasi-static tests. International Journal of Mechanical Sciences. 2018.

[24] Mohotti D, Ngo T, Mendis P, Raman SN. Polyurea coated composite aluminium plates subjected to high velocity projectile impact. Materials \& Design (1980-2015). 2013;52:1-16.

[25] Khodadadi A, Liaghat G, Bahramian AR, Ahmadi H, Anani Y, Asemani S, et al. High velocity impact behavior of Kevlar/rubber and Kevlar/epoxy composites: A comparative study. Composite Structures. 2019;216:159-67.

[26] Ahmadi H, Liaghat G. Analytical and experimental investigation of high velocity impact on foam core sandwich panel. Polymer Composites. 2018.

[27] López-Puente J, Zaera R, Navarro C. An analytical model for high velocity impacts on thin CFRPs woven laminated plates. International Journal of solids and structures. 2007;44:2837-51.

[28] Zukas JA, Nicholas T, Swift HF, Greszczuk LB, Curran DR. Impact dynamics: Wiley New York; 1982.

[29] Fatt MSH, Lin C, Revilock JrDM, Hopkins DA. Ballistic impact of GLARETM fiber-metal laminates. Composite structures. 2003;61:73-88.

[30] López-Puente J, Varas D, Loya J, Zaera R. Analytical modelling of high velocity impacts of cylindrical projectiles on carbon/epoxy laminates. Composites Part A: applied science and manufacturing. 2009;40:1223-30.

[31] Khazraiyan N, Liaghat G, Khodarahmi H, Dashtian-Gerami N. Analysis of perforation process into concrete/metal targets by rigid projectiles. Proceedings of the Institution of Mechanical Engineers, Part C: Journal of Mechanical Engineering Science. 2013;227:1454-68.

[32] Ghalami-Choobar M, Sadighi M. Investigation of high velocity impact of cylindrical projectile on sandwich panels with fiber-metal laminates skins and polyurethane core. Aerospace Science and Technology. 2014;32:142-52.

[33] Li Q, Tong D. Perforation thickness and ballistic limit of concrete target subjected to rigid projectile impact. Journal of Engineering Mechanics. 2003;129:1083-91.

\section{Appendix A}




$$
\begin{aligned}
& f_{0}(x)=-\sigma_{e}\left(N_{1}+N_{3}\right)\left(\frac{N_{2} x-1}{N_{2}^{2}}\right) \\
& f_{1}(x)=-\left(N_{1}+N_{3}\right) \frac{\left(-\sigma_{e}\left(N_{2}\left(x-x_{e}\right)-1\right)+\sigma_{h}\left(N_{2}\left(x-x_{e}\right)-1\right)\right)}{N_{2}^{2}} \\
& f_{2}(x)=-\frac{N_{4}}{N_{2}}\left[\begin{array}{l}
r^{2}+2 r \tan \theta\left(\left(x-x_{0}\right)-\frac{1}{N_{2}}\right) \\
+\tan \theta^{2}\left(\left(x-x_{0}\right)^{2}-\frac{2\left(x-x_{0}\right)}{N_{2}}+\frac{2}{N_{2}^{2}}\right)
\end{array}\right] \\
& {\left[r^{2}+2 r \tan \theta\left(\left(x-x_{0}\right)-\frac{1}{N_{2}}\right)\right.} \\
& \left.f_{3}(x)=\frac{N_{4}}{N_{2}}\right)_{+\tan \theta^{2}}\left(\begin{array}{l}
\left((x-h)^{2}-\frac{2(x-h)}{N_{2}}+\frac{2}{N_{2}^{2}}\right) \\
+h^{2}+2 h\left((x-h)-\frac{1}{N_{2}}\right)
\end{array}\right. \\
& -2 x_{0}\left(x-\frac{1}{N_{2}}\right) \\
& +x_{0}^{2}
\end{aligned}
$$




\section{Figure Captions}

Figure 1: (a) Manufactured AAC block and (b) specimen for impact tests.

Figure 2: Schematic diagram (a, b) and photograph (c) of clamping fixture.

Figure 3: Stress- displacement curve obtained by quasi static experimental tests.

Figure 4: Gas gun apparatus used for experimental test (a) main structure, (b) high pressure reservoir and solenoid valve.

Figure 5: Schematic diagram of AAC block subjected high-velocity projectile.

Figure 6: Through section (a) view of the AAC specimen and (b) schematic of the truncated conical shape.

Figure 7: Comparison of residual velocity obtained by the proposed analytical model and those of experiment.

Figure 8: Comparison of (a) non-dimensional parameters (b) relative importance of various energy absorption mechanisms for various input velocities obtained by the proposed analytical model.

Figure 9: (a) Variation of residual velocity for different projectile mass during the impact process. (b) Energy absorption vs. mass projectile.

Figure 10: (a) Variation of residual velocity vs. projectile position for different radii of projectiles. (b) Energy absorption vs. radius projectile.

Figure 11: (a) Variation of residual velocity during the impact process for different of input velocities of projectile. (b) Energy absorption vs. Input velocity.

Figure 12: (a) Variation of residual velocity vs. projectile position for different of thickness of targets. (b) Energy absorption vs. target thickness.

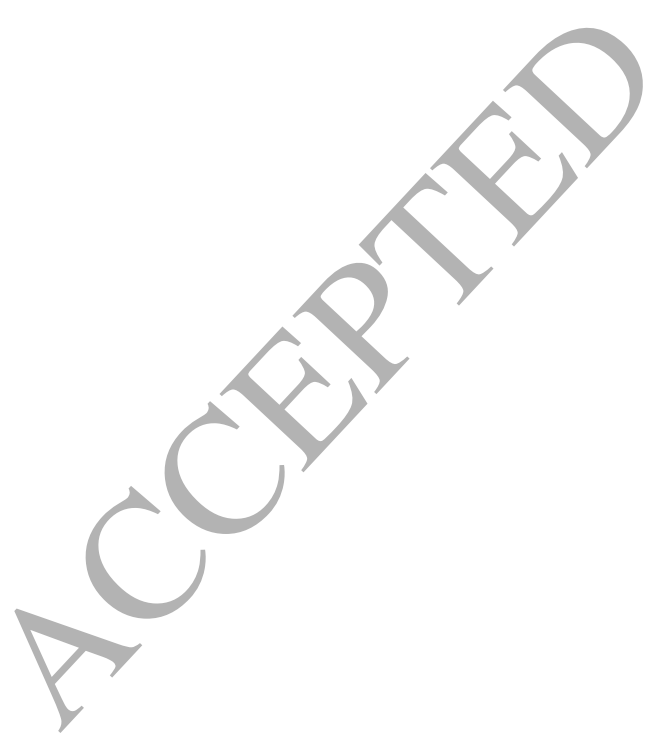




\section{Figures}
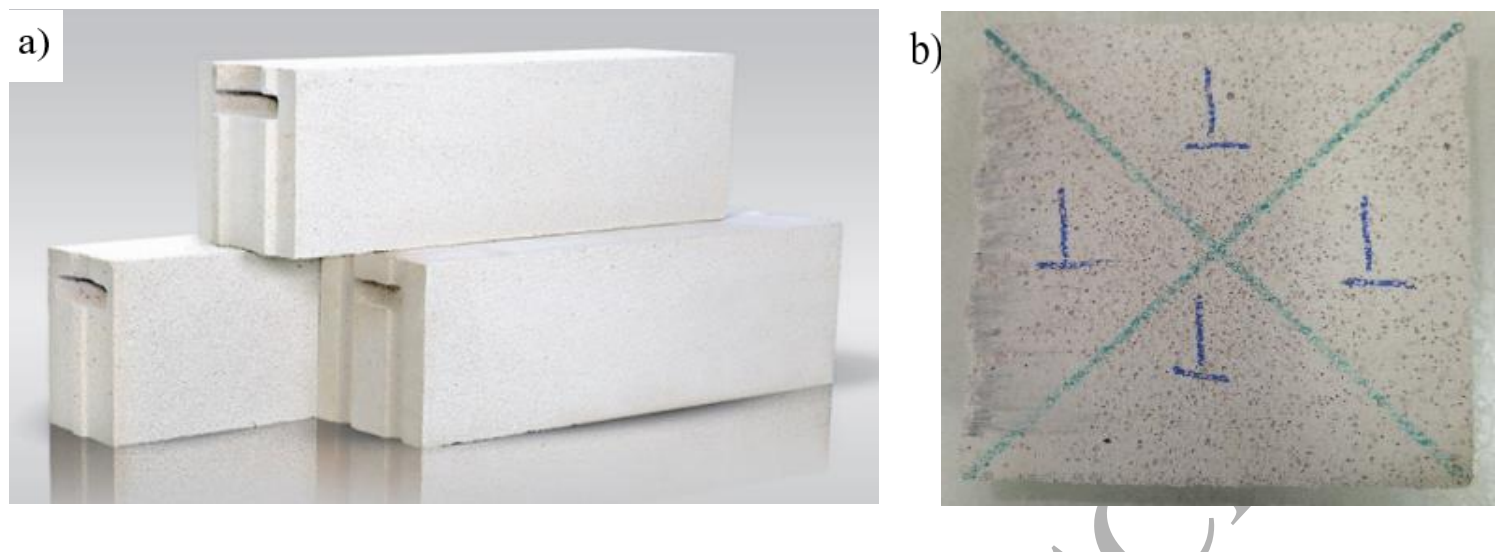

Figure 1: (a) Manufactured AAC block and (b) specimen for impact tests.
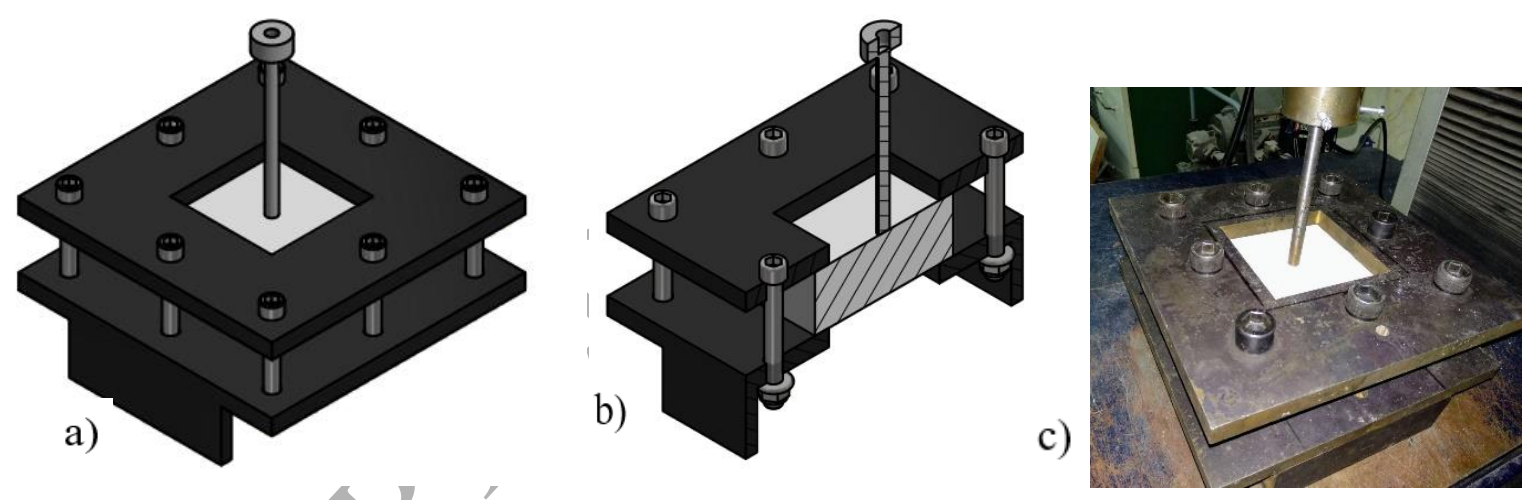

Figure 2: Schematic diagram (a,b) and photograph (c) of clamping fixture.

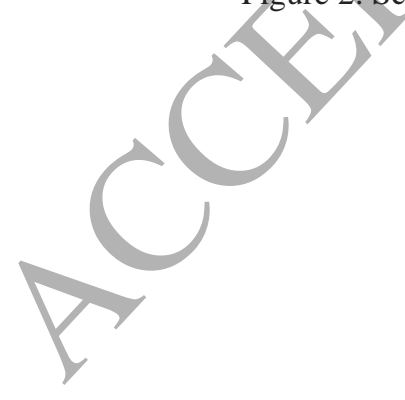




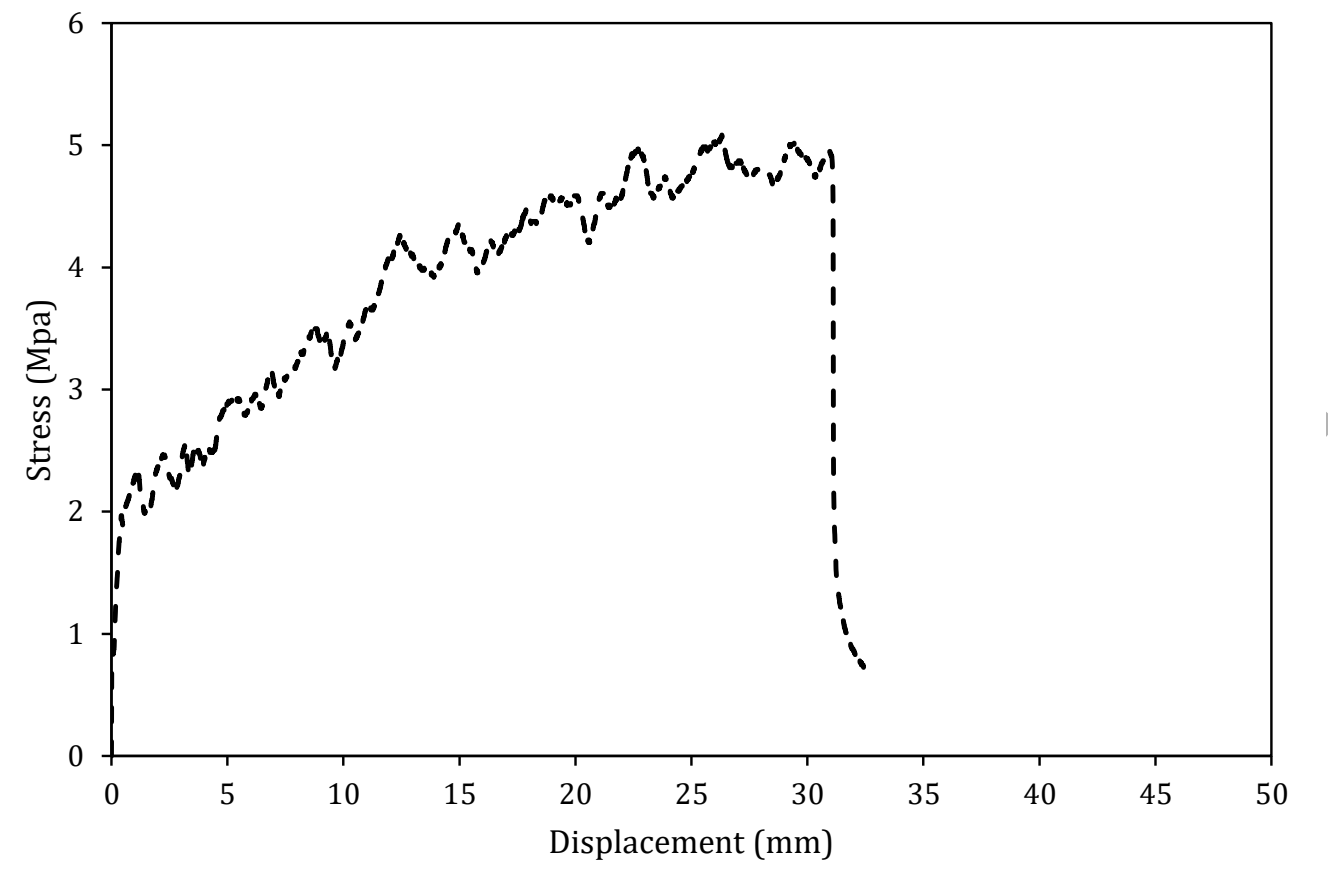

Figure 3: Stress- displacement curve obtained by quasi static experimental tests.

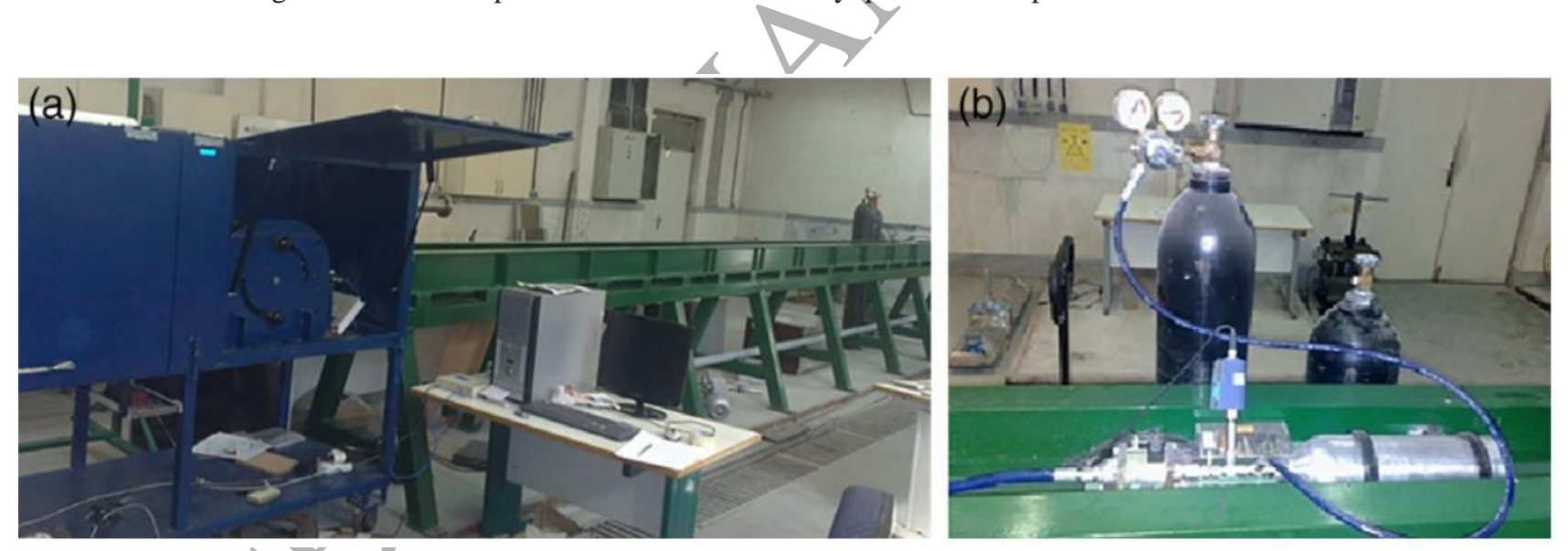

Figure 4: Gas gun apparatus used for experimental test (a) main structure, (b) high pressure reservoir and solenoid

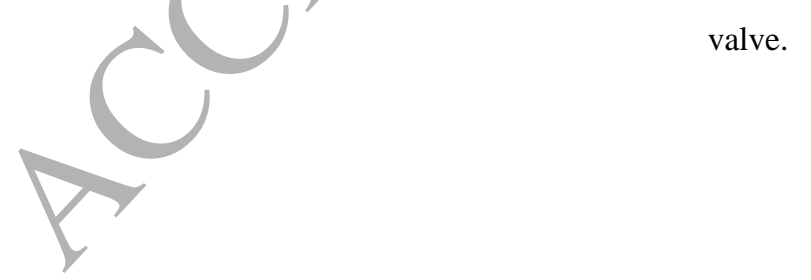




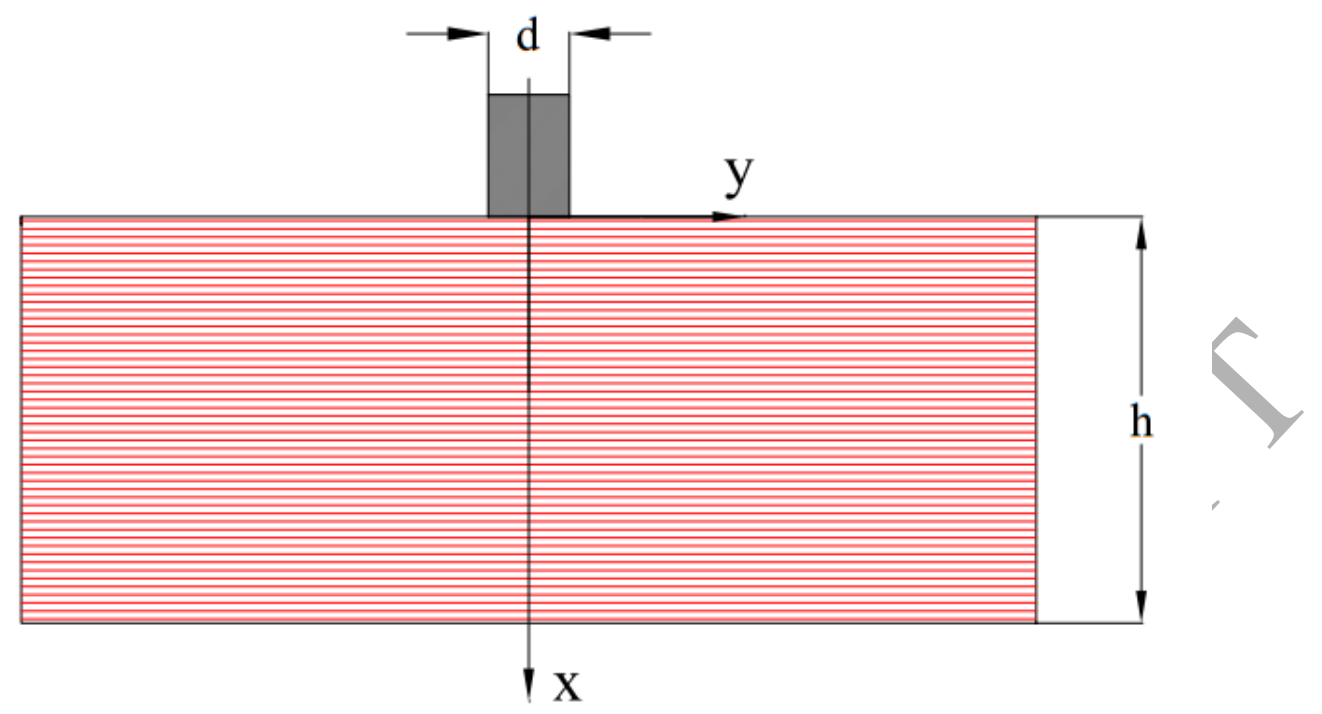

Figure 5: Schematic diagram of AAC block subjected high-velocity projectile.

a)
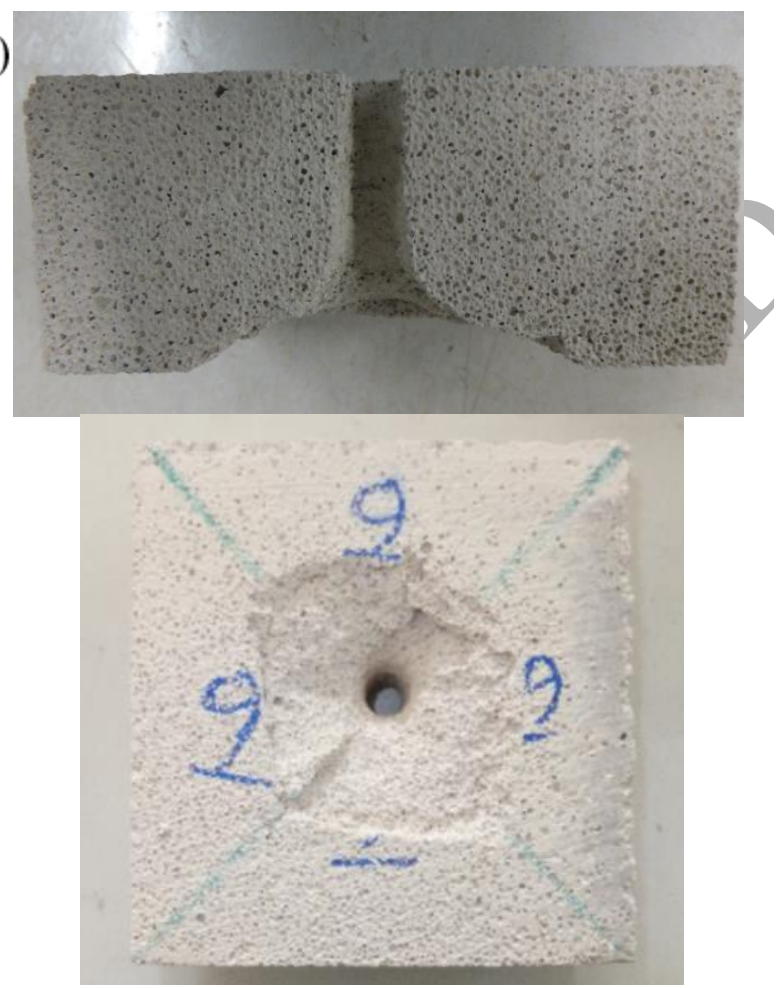

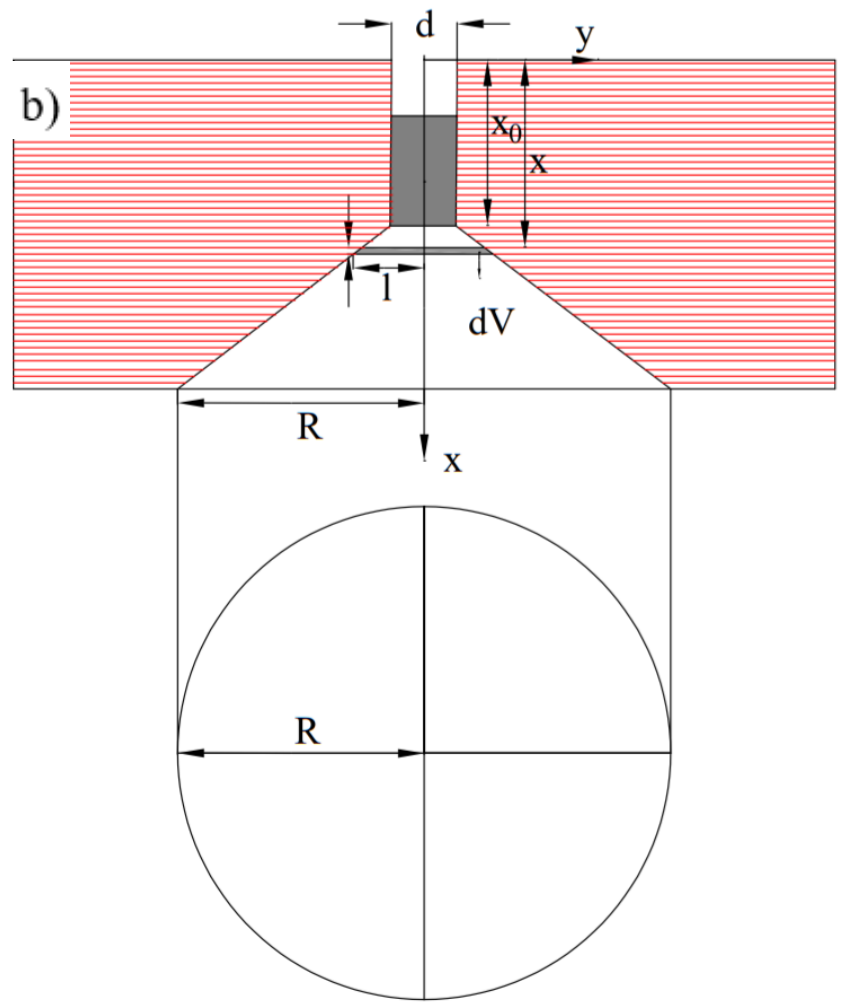

Figure 6: Through section (a) view of the AAC specimen and (b) schematic of the truncated conical shape. 


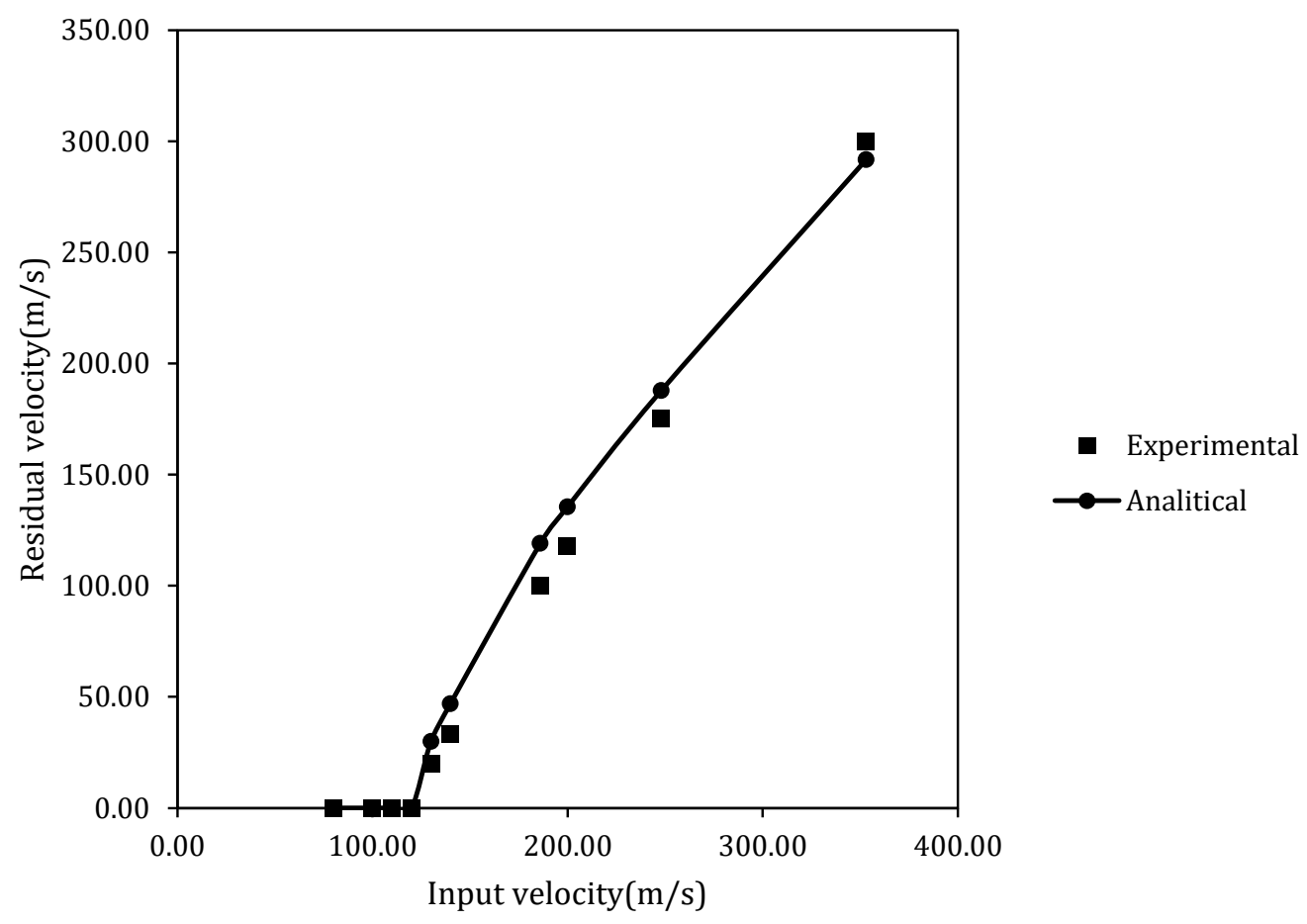

Figure 7: Comparison of residual velocity obtained by the proposed analytical model and those of experiment. 

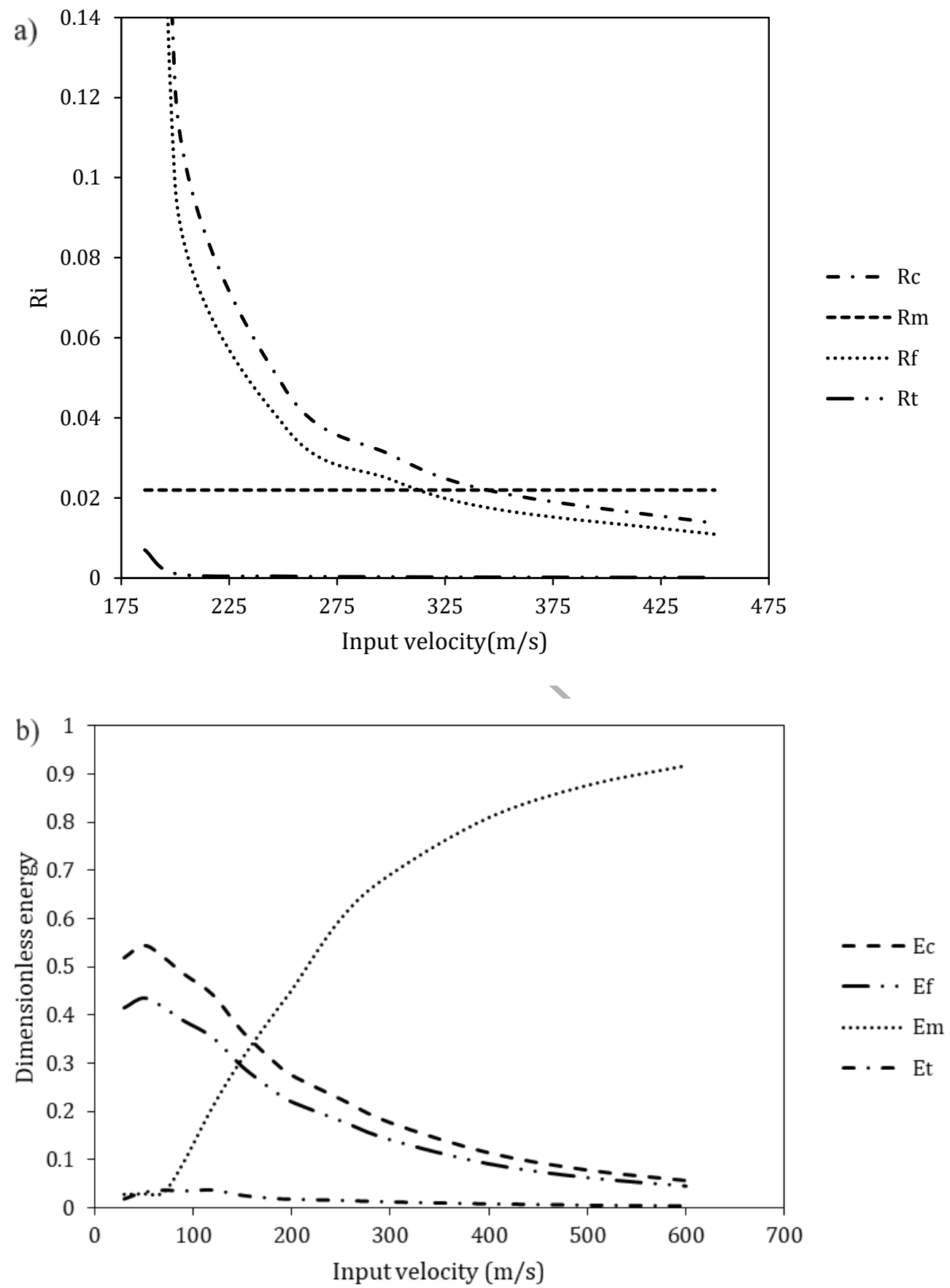

Figure 8: Comparison of (a) non-dimensional parameters (b) relative importance of various energy absorption mechanisms for various input velocities obtained by the proposed analytical model. 

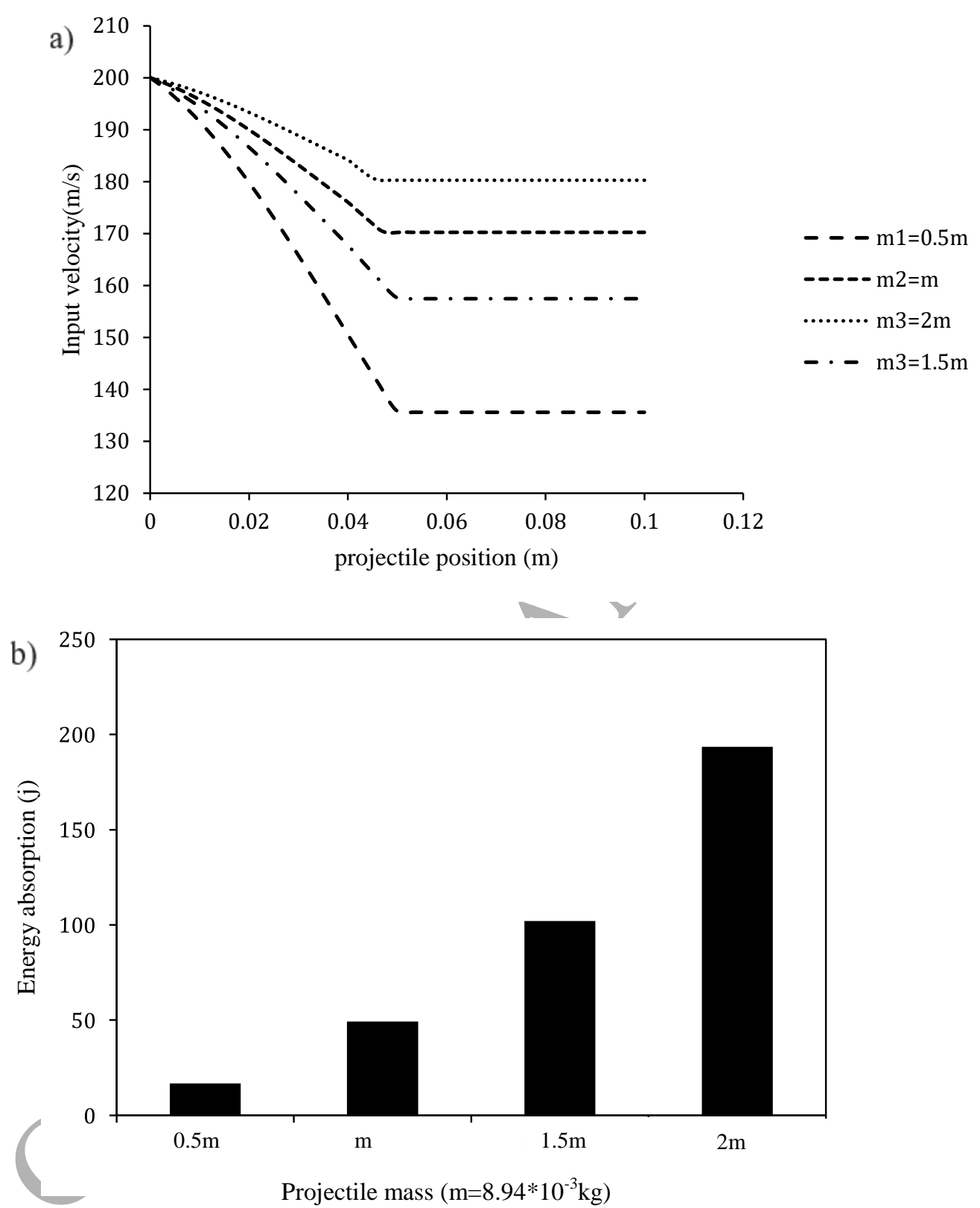

Figure 9: (a) Variation of residual velocity for different projectile mass during the impact process. (b) Energy absorption vs. mass projectile. 

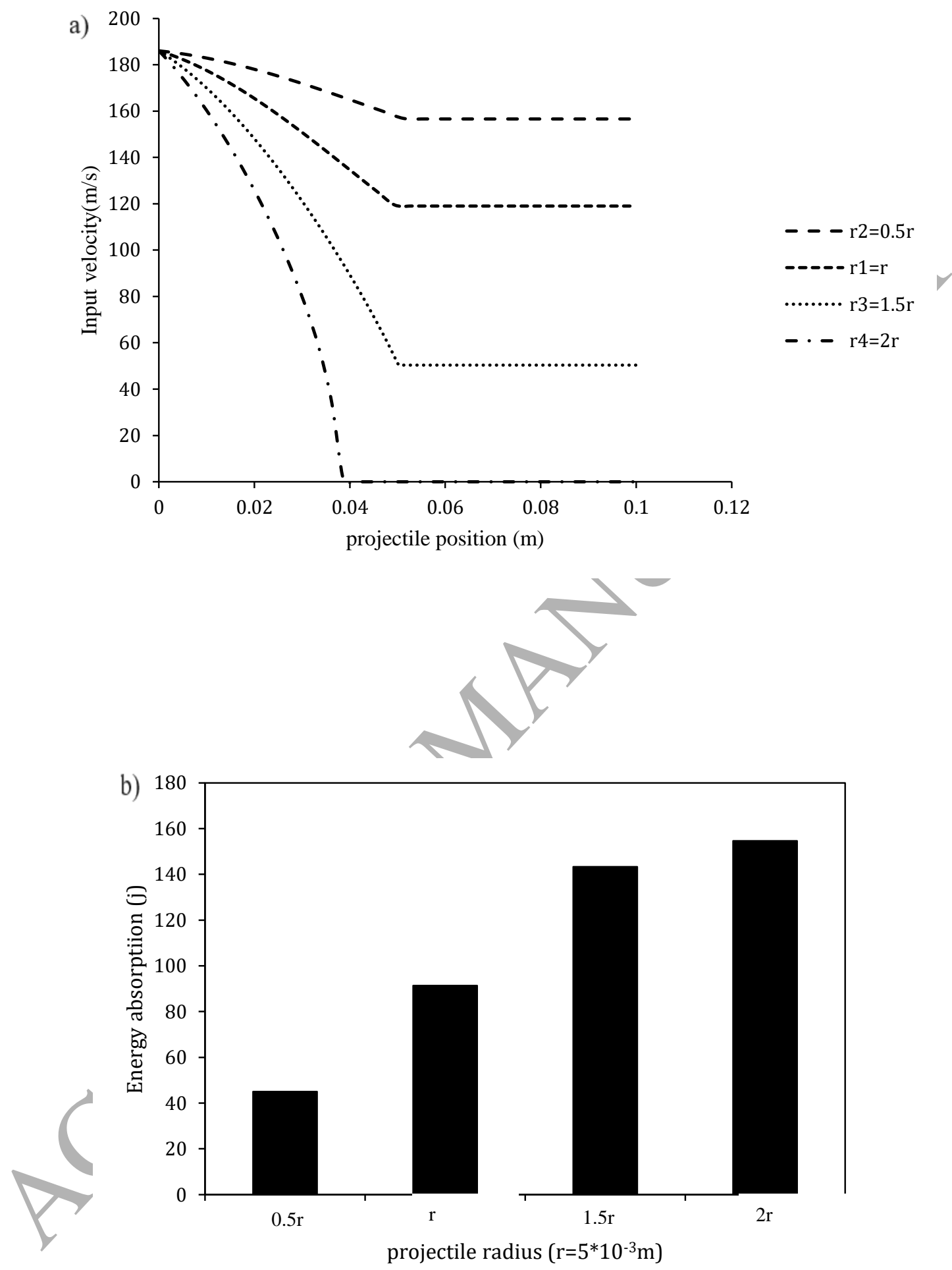

Figure 10: (a) Variation of residual velocity vs. projectile position for different radii of projectiles. (b) Energy absorption vs. radius projectile. 

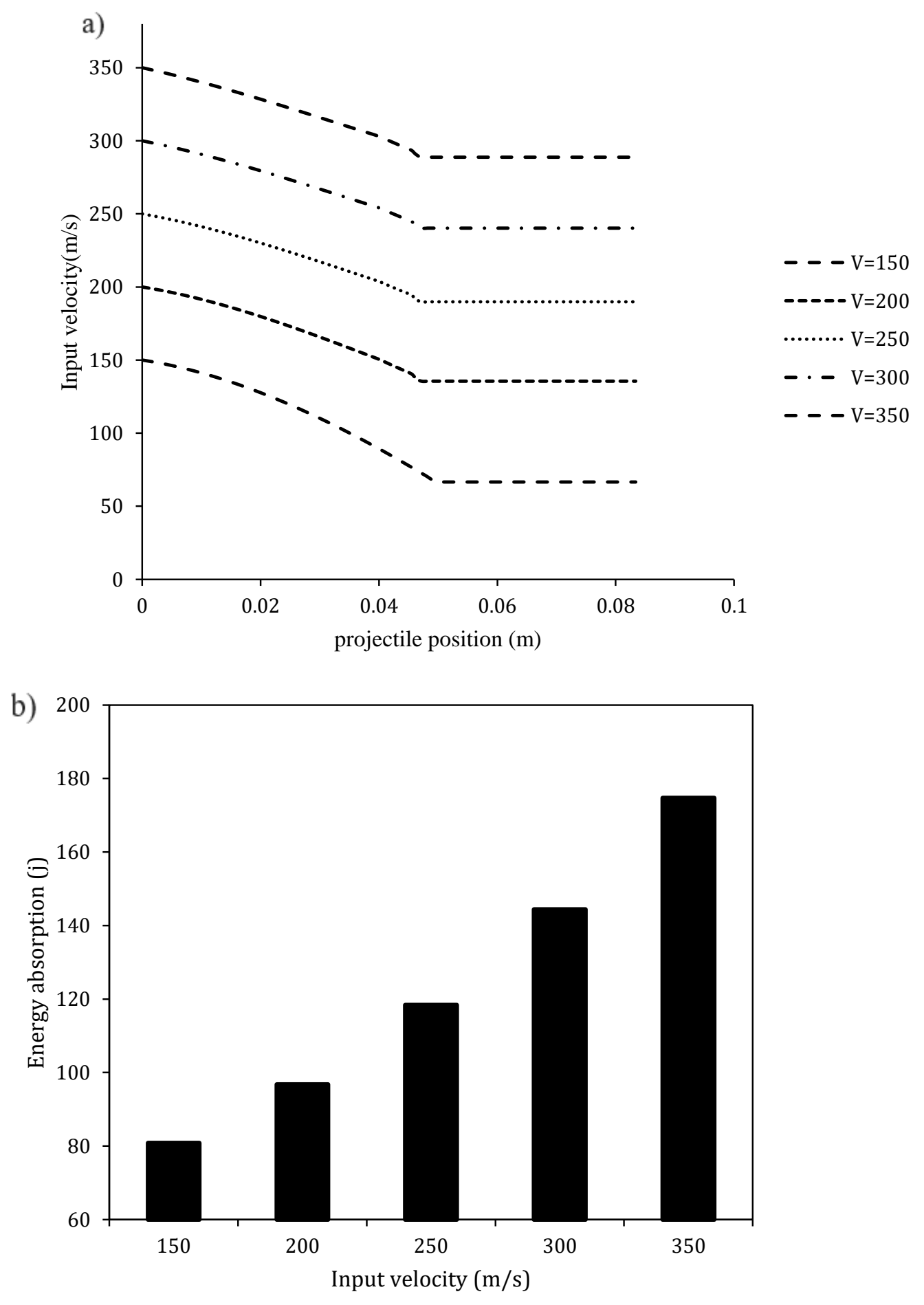

Figure 11: (a) Variation of residual velocity during the impact process for different of input velocities of projectile. (b) Energy absorption vs. Input velocity. 

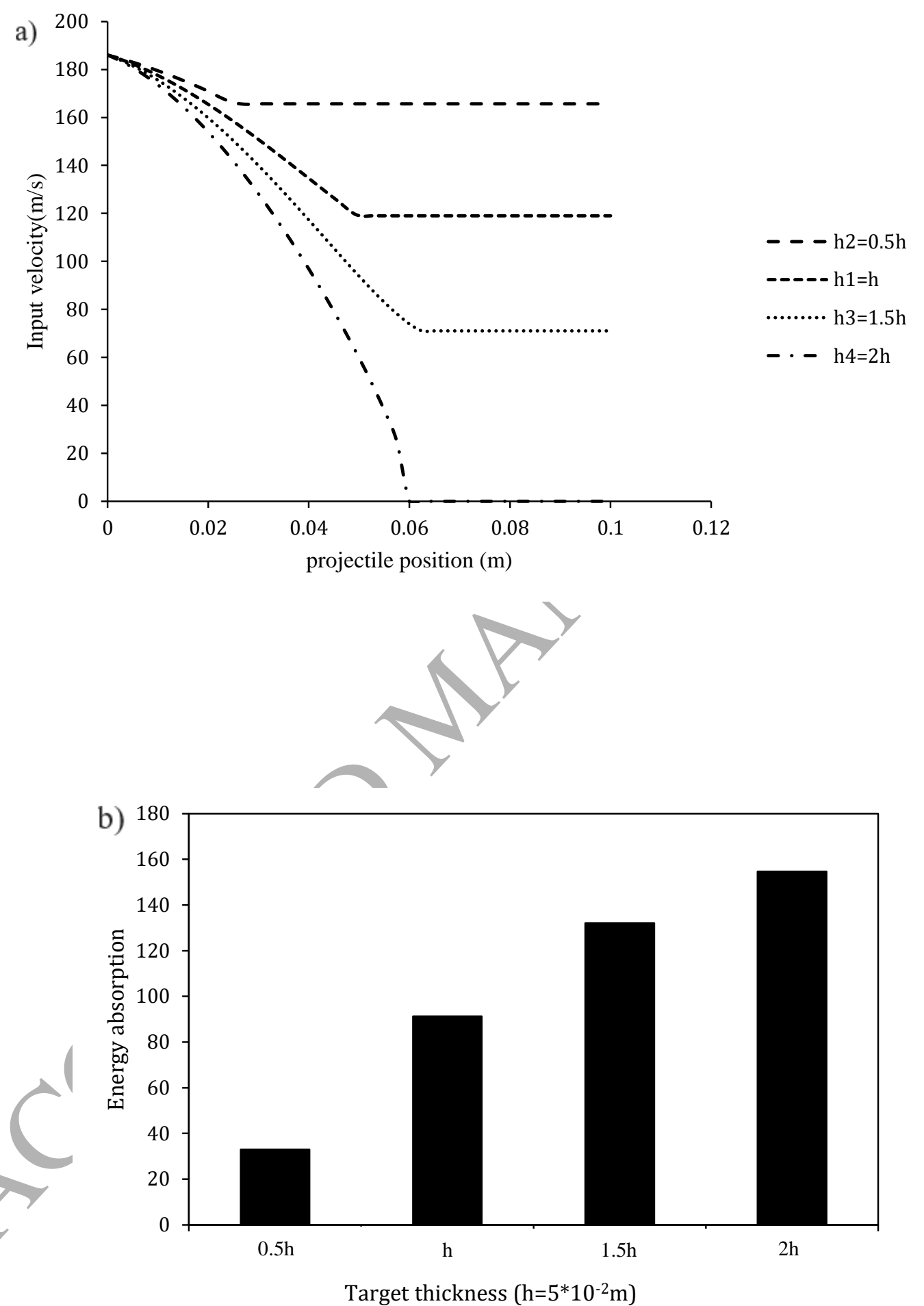

Figure 12: (a) Variation of residual velocity vs. projectile position for different of thickness of targets. (b) Energy absorption vs. target thickness. 


\section{Tables}

Table 1: Mechanical properties of AAC block.

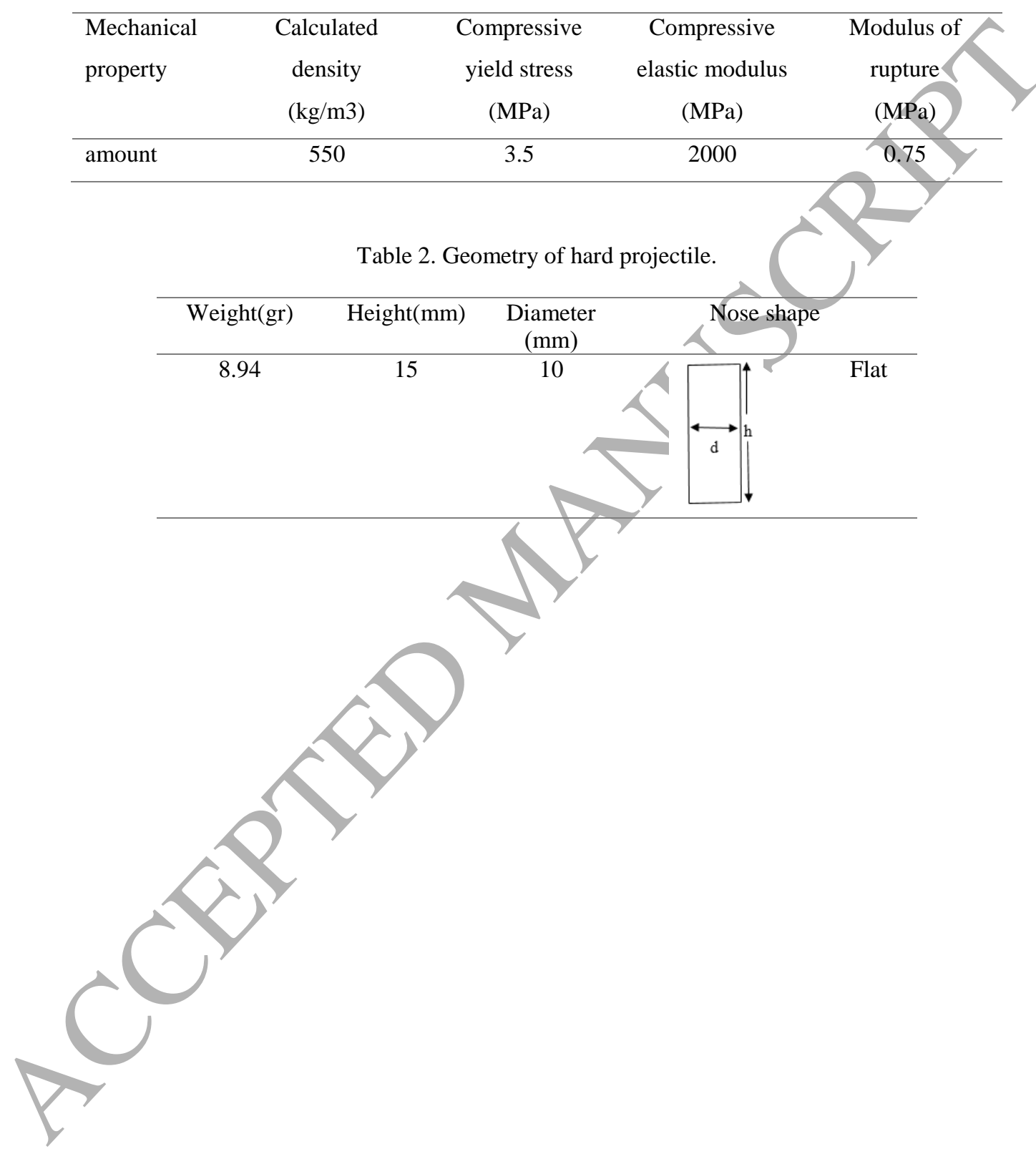




\section{Graphical Abstract}

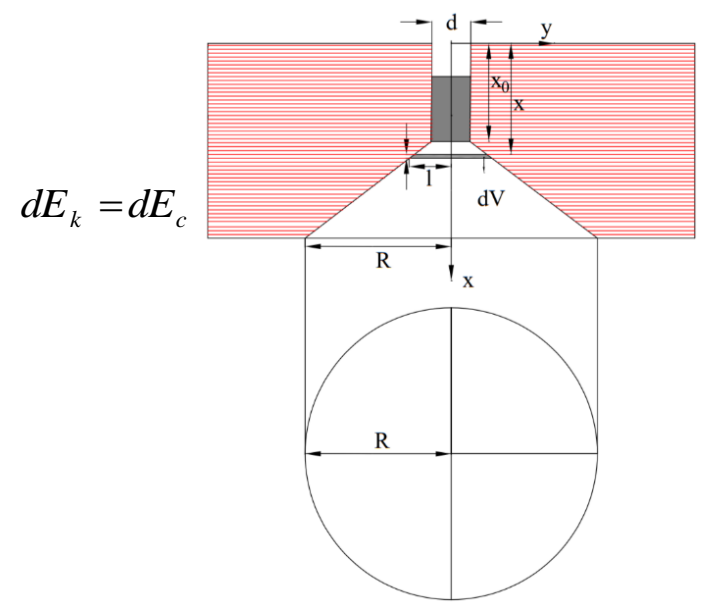

Energy balance

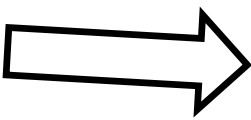

Schematic of through section of truncated conical shape of AAC subjected by flat ended projectile
(n)
$V(0)=V_{i}$

Four different mechanisms: AAC crushing $E_{c}$, $\operatorname{energy} E_{t}$, plug kinetic energy $E_{m}$ and frictior

Initial value problem (IVP) solved to obtain velocity of projectile
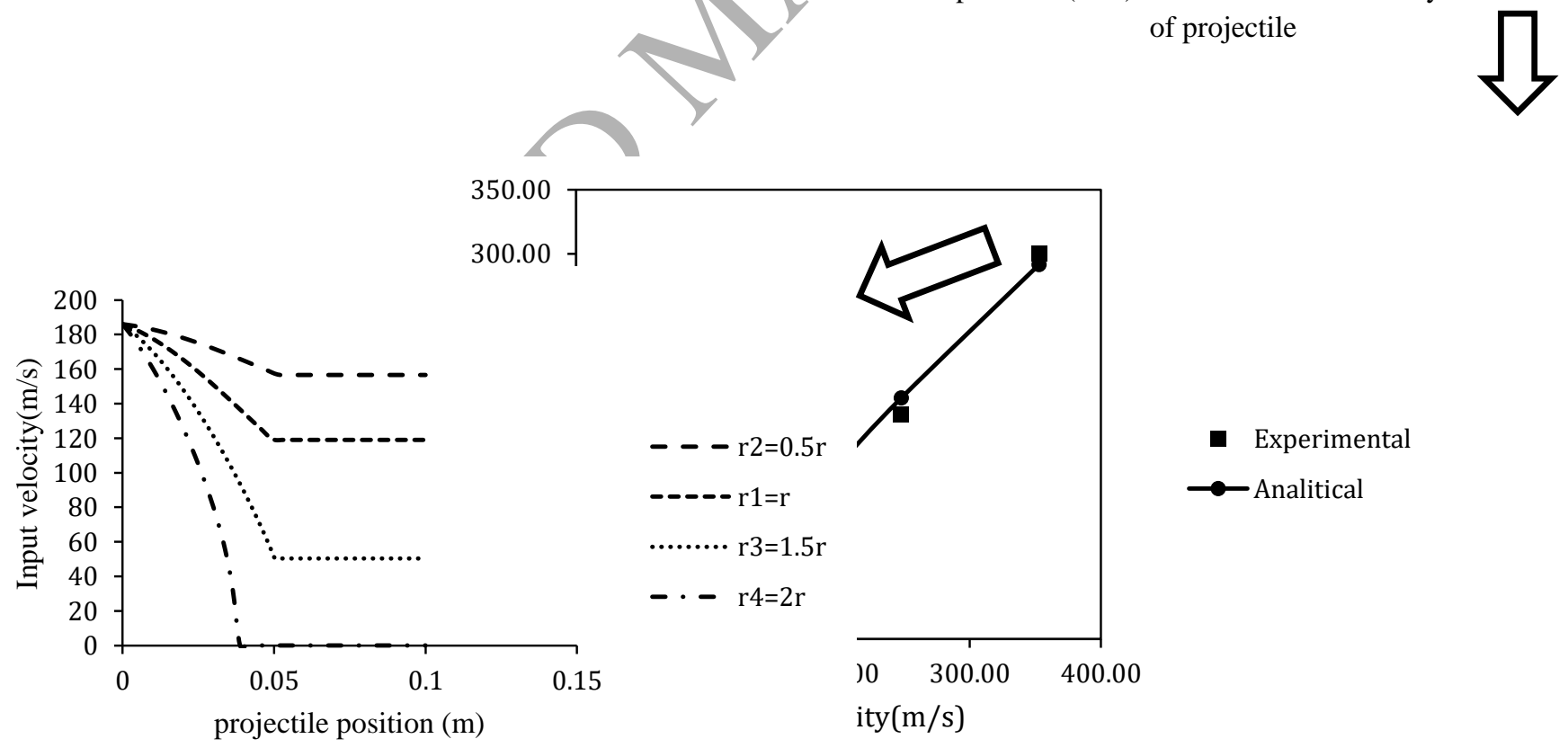

Influence of various parameters such as projectile mass, projectile

Comparison of residual velocity for varic radius, input velocity and target thickness on high velocity impact obtained by the proposed analytical and th behavior 